\title{
Signs of alveolar bone damage in early stages of periodontitis and its prevention by stimulation of cannabinoid receptor 2 . Model in rats
}

\author{
César A. Ossola', Julieta A. Rodas', Noelia B. Balcarcel', Julia I. Astrauskas', Juan C. Elver- \\ din' and Javier Fernández-Solari' ${ }^{1,2}$
}

' Universidad de Buenos Aires, Facultad de Odontología, Cátedra de Fisiología, Buenos Aires, Argentina.

${ }^{2}$ Consejo Nacional de Investigaciones Científicas y Técnicas, Buenos Aires, Argentina.

\begin{abstract}
The aims of the present study were, first, to identify signs of alveolar bone damage in early stages of experimental periodontitis (EP) and, second, to assess its possible prevention by treatment with cannabinoid receptor 2 agonist HU 308. Experimental periodontitis was induced by injections of lipopolysaccharide (LPS) $(1 \mathrm{mg} / \mathrm{ml})$ in gums surrounding maxillary and mandibular first molar, 3 days per week, and untreated controls were kept for comparison. Then, a 3-week study was conducted including eighteen new rats (six rats per group): 1) controls; 2) experimental periodontitis rats; and 3) experimental periodontitis rats treated daily with $\mathrm{HU} 308$ $(500 \mathrm{ng} / \mathrm{ml})$. After euthanasia, alveolar bone loss was assessed by morphometric and histomorphometric techniques, and the content of prostaglandin $E_{2}\left(P G E_{2}\right)$ in gingival tissue was evaluated by radioimmunoassay. The first signs of alveolar bone loss were apparent at 3 weeks of experimental periodontitis $(\rho<0.05)$ in the mandibular first molar, but there was no
\end{abstract}

detectable change at 1 week, leading us to establish 3 weeks as an early stage of experimental periodontitis. Rats subjected to 3-week experimental periodontitis showed less interradicular bone volume, less whole bone perimeter and fewer bone formation areas, and higher periodontal space height, bone resorption areas, number of osteoclasts and gingival content of prostaglandin $E_{2}$ than controls, while $H U 308$ prevented, at least partially, the deleterious effects $(\rho<0.001)$. We can conclude that a 3-week term of lipopolysaccharide-induced periodontitis in rats provides a valid model of the early stage of the disease, as emerging damage is observed in bone tissue. Furthermore, harmful effects at 3 weeks could be prevented by local stimulation of cannabinoid receptor 2, before greater damage is produced.

Received: March 2020; Accepted: July 2020.

Keywords: periodontitis- cannabinoids- alveolar bone lossprostaglandin $E_{2}$.

\section{Signos de daño óseo alveolar en estadios tempranos de periodontitis y su prevención por estimulación del receptor cannabinoide 2 . Modelo en ratas microcisalhamento do cimento resinoso}

\begin{abstract}
RESUMEN
El objetivo del presente trabajo fue, en primer lugar, identificar signos de daño óseo alveolar en estadios tempranos de periodontitis experimental y, en segundo lugar, evaluar su posible prevención mediante el tratamiento con el agonista del receptor cannabinoide 2, HU 308. La periodontitis experimental fue inducida por inyecciones de lipopolisacárido $(1 \mathrm{mg} / \mathrm{ml})$ en la encía circundante al primer molar maxilar y mandibular, 3 dias por semana, en tanto que controles no tratados fueron mantenidos para la comparación. Posteriormente, un estudio de 3 semanas con dieciocho nuevas ratas (seis por grupo) fue desarrollado: 1) controles; 2) ratas con periodontitis experimental, y 3) ratas con periodontitis experimental tratadas diariamente con $H U 308$ (500 $\mathrm{ng} / \mathrm{ml})$. Luego de la euthanasia, la pérdida ósea alveolar fue evaluada por técnicas morfométricas e histomorfométricas, y el contenido de prostaglandina $E_{2}$ en el tejido gingival fue determinado por radioinmunoensayo. Los primeros signos de pérdida ósea alveolar fueron evidentes a las 3 semanas de inducción de periodontitis experimental $(\rho<0.05)$ en el primer molar mandibular, mientras
\end{abstract}

que no hubo cambios detectables luego de 1 semana de inducción, hecho que nos condujo a establecer a las 3 semanas como un estadio temprano de periodontitis experimental, Las ratas sometidas a perdiodontitis experimental de 3 semanas mostraron menor volumen óseo interradicular, menor perímetro óseo y menos áreas de formación ósea, y mayor altura del espacio periodontal, más áreas de reabsorción ósea, mayor número de osteoclastos y mayor contenido gingival de prostaglandina $E_{2}$, en comparación a los controles, mientras que el tratamiento con HU 308 previno, al menos parcialmente, los efectos deletéreos $(\rho<0.001)$. Podemos concluir que el término de 3 semanas de periodontitis inducida por lipopolisacárido es un modelo válido de estadio inicial de la enfermedad experimental, dado que se evidencia daño emergente en el tejido óseo. Asimismo, los efectos deletéreos de 3 semanas podrían ser prevenidos por la estimulación local del receptor cannabinoide 2, antes que un daño mayor sea producido.

Palabras clave: periodontitis, cannabinoides, pérdida ósea alveolar, prostaglandina $E_{2}$. 


\section{INTRODUCTION}

Initial stages of periodontal diseases include gingivitis and incipient chronic periodontitis. Gingivitis is defined as an inflammation of the gingival tissue, while periodontitis involves the loss of attachment of periodontal tissues from the tooth and the loss of alveolar bone. Gingivitis is reversible, whereas regeneration after the destruction caused by periodontitis is not predictably achievable in humans ${ }^{1}$. Even though most periodontal diseases are known to occur in susceptible subjects, their onset also depends on colonization by bacteria and presence of bacterial products ${ }^{2}$. Lipopolysaccharide (LPS), a toxin produced by gram-negative microorganisms, can cause an inflammatory process, with the consequent damage in the toothinsertion tissues ${ }^{3}$. In the host tissues, LPS stimulates phagocytes to increase the production of cytokines such as TNF $\alpha$, IL-1 $\beta$, IL-6, IL-10, IL-12 and IL-154. Those mediators are responsible for a large number of cellular events, including the synthesis of $\mathrm{PGE}_{2}{ }^{5}$, a potent stimulator of bone resorption associated with loss of periodontal attachment tissues ${ }^{6}$. Additionally, in animals with periodontitis, $\mathrm{PGE}_{2}$ has been found to increase in the submandibular gland, where it seems to function as an inhibitor of salivary secretion ${ }^{7}$. Thus, although colonization by pathogenic microbes is the primary origin of damage in periodontal diseases, the host immuneinflammatory response plays a critical role in the development of tissue injury resulting in the loss of connective tissue and alveolar bone ${ }^{8}$.

The cellular and humoral response deployed in bacterial processes involves the endocannabinoid system $(E C S)^{9,10}$, which is an intercellular communication network that includes receptors, endogenous ligands and a series of enzymes responsible for ligand synthesis and breakdown. Cannabinoid receptors type 1 (CB1r) and type 2 (CB2r) are the main specific cannabinoid receptors, whereas transient receptor potential vanilloid type 1 is the most throughly studied unspecific receptor ${ }^{11}$. According to the classical concept and even though it has been submitted to revisions, CB1 is highly expressed in the central nervous system and to a lesser extent, in peripheral tissues. Conversely, CB2 is expressed mainly in peripheral tissues and cells such as monocytes, macrophages, lymphocytes and bone cells ${ }^{12}$. However, the stimulation of ECS has been associated with anti-inflammatory effects through both $\mathrm{CB} 1^{13,14}$ and $\mathrm{CB} 2^{15}$ receptors. In previous studies, we have shown that in a sixweek LPS-induced periodontitis model in rats, daily application of a CB2r synthetic agonist, HU 308, attenuated alveolar bone loss and reduced the level of inflammatory mediators in gums ${ }^{16}$.

The aims of this study were, firstly, to identify early alveolar bone damage in periodontal disease in order to establish initial stages of the disease in an experimental model, and secondly, to evaluate the effects of the treatment with a CB2 receptor agonist, HU 308, on the oral health of rats submitted to early periodontitis, and compare these effects with those found in the pattern of long-term illness.

\section{MATERIALS AND METHODS}

\section{Animals}

Adult male Wistar rats (350 g) from the authors' own colony were kept in group cages in an animal room with a 12-hour light photoperiod (0700 to 1900 ), room temperature maintained at $22^{\circ} \mathrm{C}$ to $25^{\circ} \mathrm{C}$, and free access to rat chow and tap water. The experimental procedures performed were approved by the Animal Care Committee of the Dental School of the University of Buenos Aires, Buenos Aires, Argentina and carried out in accordance with guidelines of the National Institutes of Health.

\section{Time range studies}

Since our previous studies had been based on a six-week lipopolysaccharide-induced periodontitis model, we intended to achieve a model of periodontitis with emerging damage. To this end, we conducted a first experiment based on temporal studies of lipopolysaccharide-periodontitis induction at 1, 3 and 6 weeks. For each term of induction, twelve rats were divided into two groups, each group containing six rats: 1) control rats, and 2) rats submitted to experimental periodontitis. Periodontitis was induced by injecting $20 \mu \mathrm{l}$ of lipopolysaccharide (1 $\mathrm{mg} / \mathrm{ml}$ ) from Escherichia coli into the vestibular and lingual gingiva of the maxillary and mandibular first molars and into the interdental space between the first and second maxillary and mandibular molars (60 $\mu \mathrm{l}$ of lipopolysaccharide per tooth and $240 \mu \mathrm{l}$ per rat at each time of injection). Gingival injections were all performed using a 13-mm 27-gauge microfine insulin syringe. Control rats received no injection during the experiments. 


\section{CB2 receptor studies}

In a second experiment, eighteen rats were distributed into three groups of six rats per group: 1) control rats; 2) rats submitted to EP; and 3) rats submitted to EP and treated with HU 308, an agonist of CB2r. Periodontitis was induced as described for the preliminary studies, while control rats received no injection during the experiment. This protocol of injections was executed for a period of 3 weeks on days 1,3 , and 5 of each week, based on a previously described method ${ }^{14,17}$. Gingival injections were applied using a 13-mm 27-gauge microfine insulin syringe.

\section{Topical treatment with a CB2 receptor agonist}

HU 308 ([(1R,2R,5R)-2-[2,6-dimethoxy-4-(2methyloctan-2-yl) phenyl]-7,7-dimethyl-4-bicyclo [3.1.1] hept-3-enyl] methanol) was prepared by dissolving the powdered drug in 100\% ethanol and diluting it in saline, containing approximately $1 \%$ ethanol, to obtain a final concentration of $500 \mathrm{ng} / \mathrm{ml}$ with which to treat animals.

The volume of each topical application was 200 $\mu 1$ per tooth, resulting in $800 \mu$ per animal when treatment was performed. As mentioned above, the second experiment consisted of a 3-week study in which group 3 animals received a daily topical application of HU 308 at sites of LPS during the 3 weeks of the experiment. The optimal dose of HU 308 was based on previous reports using anandamide, but mainly using methanandamide, a selective synthetic agonist of CB1 receptor ${ }^{14,18}$, on oral tissues in vivo concomitantly with the dose response curves in these preliminary studies.

Macroscopic examination of periodontal bone loss: distance and width methods

Immediately after euthanasia of the rats, hemimandibles were resected, defleshed, and stained with $1 \%$ aqueous methylene blue to delineate the cementoenamel junction (CEJ) and the alveolar crest $(\mathrm{AC})^{19}$. A stereomicroscope and a digital calliper were used to measure three buccal and three lingual/palatal distances (mesial, central, and distal), from the CEJ to the $\mathrm{AC}^{14}$. The sum of the three distances on each side of molars was used as a measure of alveolar bone loss (ABL) in millimetres. Thus, ABL was assessed on the buccal side, palatal/ lingual side and also as whole tooth of the first upper and lower molars. Mandibular alveolar process width was measured in the mandibular first molar area. Distance between a point located at the central root level of the buccal surface and another equally located on the lingual surface was measured in the mandibles in millimetres using a digital calliper. This examination was performed for all the groups in the first and second experiments.

\section{Histological analysis}

Hemimandibles on the opposite side to those used for macroscopic examinations were fixed in formalin buffer. After 3 days, they were decalcified in $10 \%$ EDTA pH 7 for 45 days. Then hemimandibles were dehydrated with ethyl alcohol and clarified with xylene. Finally, the sector containing the first molar of each decalcified hemimandible was embedded in paraffin at $56^{\circ} \mathrm{C}$ to $58^{\circ} \mathrm{C}$. Under the stereomicroscope, sections oriented mesial-distally of each mandibular first molar were cut from the paraffin blocks using a microtome. Sections $5 \mu \mathrm{m}$ thick were stained with haematoxylin and eosin (H\&E), and histomorphometric evaluation was performed on digitized microphotographs using imaging software. Interradicular bone loss was evaluated by measuring the periodontal space height, plotting 10 equidistant lines between the alveolar crest and the cementum of the furcation zone. The length of the lines was measured and the mean value was calculated. Additionally, ABL was assessed by the following parameter: bone volume (B.Ar)/total volume (T.Ar) $(\%)=$ fraction of TV corresponding to bone tissue. T.Ar was taken as bone tissue plus bone marrow and periodontal ligament ${ }^{20}$. The remaining histomorphometric parameters were evaluated in the bone of the interdental septum located between the first and second lower molars. These parameters were: whole perimeter of the interdental septum, in $\mu \mathrm{m}$; bone formation areas, in $\%$ as $\mathrm{Ob} . \mathrm{S} / \mathrm{BS}$ (osteoblast surface related to total bone surface); bone resorption areas, in \% as ES/ BS (eroded surface related to total bone surface), and number of osteoclasts ${ }^{21,22}$, as N.Oc/mm, in the cervical third of the mentioned septum. Histological analysis was performed for all the groups in the second experiment.

\section{Radioimmunoassay of $\mathbf{P G E}_{2}$}

To determine $\mathrm{PGE}_{2}$ content, gingival tissue surrounding first molar was homogenized in 500 $\mathrm{ml}$ absolute ethanol and after centrifugation, 
supernatants were dried in a centrifugal vacuum concentrator at room temperature. Residues were then resuspended with buffer, and antiserum was used as described in Mohn et al. ${ }^{23}$. Sensitivity of the assay was $12.5 \mathrm{pg}$ per tube. The cross-reactivity of $\mathrm{PGE}_{2}$ and $\mathrm{PGE}_{1}$ was $100 \%$, but the cross-reactivity of other prostaglandins was $0.1 \%$. The intra- and inter-assay coefficients of variation for $\mathrm{PGE}_{2}$ were $8.2 \%$ and $12.0 \%$, respectively. The results were expressed in picograms of PGE per milligram of wet weight, since the protocol of PGE extraction from the tissue includes homogenization in ethanol, which interferes with protein determination. This evaluation was performed for all the groups in the first and second experiments.

\section{Statistical analysis}

Data were expressed as mean \pm standard error of the mean. Results were evaluated by one-way analysis of variance followed by the Tukey multiple comparisons test for unequal replicates. Only the number of osteoclasts was analysed using the Kruskal-Wallis nonparametric test. All analyses were conducted with Prism software and differences with $\mathrm{P}$ values $<0.05$ were considered statistically significant.

\section{RESULTS}

\section{Time range studies}

- Alveolar bone loss: distance and width methods

After 1 week of LPS injections, ABL measured by the distance method did not differ between control and LPS groups in either upper or lower first molars (Table 1). However, a significant alveolar bone loss was noticeable after 3 weeks of LPS induction, especially when whole teeth where assessed (Table $2)$. Furthermore, the differences described were stronger after 6 weeks of LPS induction, when both sides of upper and lower first molars as well as the whole tooth showed an increase in alveolar bone loss in LPS compared to control group (Table 3).

ABL measured by the width method in the mandible did not reveal changes between control and EP group after 1 and 3 weeks of procedure. In contrast, the width of the lower alveolar process was significantly lower in the LPS than in control rats after 6 weeks of induction (Table 3).

\section{- Radioimmunoassay of prostaglandin $E_{2}$} $\mathrm{PGE}_{2}$ content was evaluated as a marker of inflammatory response in gingival tissue surrounding the first molar. $\mathrm{PGE}_{2}$ content measured by RIA was markedly higher in gingival tissue after 1, 3 and 6 weeks of LPS injections in comparison to the control group. Results for 1, 3 and 6 weeks are shown at the bottom of Tables 1, 2 and 3, respectively.

CB2 receptor stimulation in early stageexperimental periodontitis rats - Three-week studies

- Alveolar bone loss: distance and width methods

In early stage-experimental periodontitis rats, alveolar bone loss measured through the distance method did not show major changes among groups in the first upper molar when buccal and palatal sides were analysed separately. In contrast, the early-stage experimental periodontitis group experienced higher alveolar bone loss than control group at the lingual side of the first lower molar,

\begin{tabular}{|c|c|c|c|c|}
\hline \multicolumn{3}{|c|}{ Macroscopic ABL (mm) } & \multirow{2}{*}{$\begin{array}{c}\text { Control } \\
2.38 \pm 0.60\end{array}$} & \multirow{2}{*}{$\begin{array}{c}\text { LPS } \\
2.54 \pm 0.56\end{array}$} \\
\hline \multirow{6}{*}{ Distance } & \multirow{3}{*}{ First upper molar } & Buccal & & \\
\hline & & Palatal & $2.83 \pm 0.78$ & $2.80 \pm 0.53$ \\
\hline & & Whole tooth & $5.21 \pm 1.15$ & $5.33 \pm 1.03$ \\
\hline & \multirow{3}{*}{ First lower molar } & Buccal & $2.45 \pm 0.19$ & $2.57 \pm 0.45$ \\
\hline & & Lingual & $3.56 \pm 0.34$ & $3.70 \pm 0.50$ \\
\hline & & Whole tooth & $6.01 \pm 0.46$ & $6.27 \pm 0.58$ \\
\hline Width & First lower molar & & $2.62 \pm 0.04$ & $2.53 \pm 0.02$ \\
\hline \multicolumn{2}{|c|}{ Gingival $\mathrm{PGE}_{2}(\mathrm{pg} / \mathrm{mg}$ tissue) } & & $87.30 \pm 12.99$ & $154.79 \pm 21.74^{*}$ \\
\hline
\end{tabular}




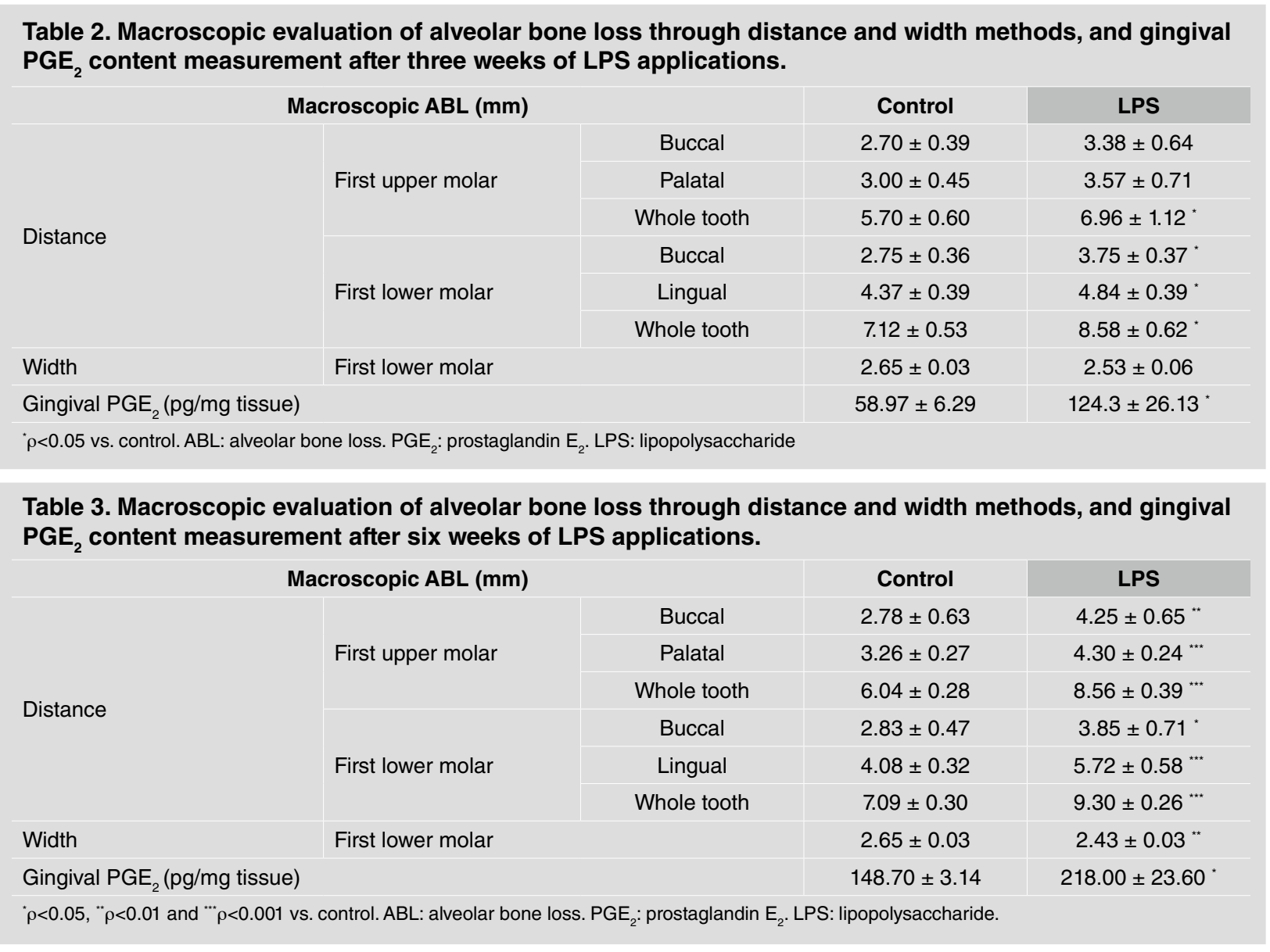

whereas this increase was significantly prevented in HU 308-treated group (Table 4). The differences mentioned for the lingual side were not detectable on the buccal side of the mandibles, except for the difference between the control and LPS groups. In turn, when the whole tooth was evaluated, both upper and lower first molars evidenced the preventive effect of HU 308 treatment on alveolar bone loss, increased by lipopolysaccharide. In the same 3-week study, alveolar bone loss measured by the width method did not exhibit significant differences among control, early stage-experimental periodontitis and HU 308 early-stage experimental periodontitis groups in the lower first molar (Table 4).

\section{- Histological analysis}

In the analysis of the interradicular bone of the first lower molar, the early-stage experimental periodontitis and HU 308 early-stage experimental periodontitis groups exhibited an increase in the periodontal space compared to the control group, but did not differ significantly from each other after the 3 week-treatment (Fig. 1A and B). On the other hand, the evaluation of the alveolar bone area, represented as B.Ar/T.Ar (\%), revealed that earlystage experimental periodontitis rats had a lower value than control rats, while that reduction was prevented, at least partially, by the HU 308 treatment (Fig. 1C).

In the analysis of the interdental septum bone, the early-stage experimental periodontitis group revealed lower whole perimeter of the interdental septum, less bone formation areas, more bone resorption areas and higher quantity of osteoclasts than the control group. However, HU 308 treatment reversed all altered records, showing longer perimeter of whole septum, more formation areas, fewer resorption areas and fewer osteoclasts than the early stage-experimental periodontitis group (Fig. 2).

\section{- Radioimmunoassay of prostaglandin $E_{2}$}

Although early-stage experimental periodontitis caused a remarkable increase in prostaglandin $E_{2}$ 


\begin{tabular}{|c|c|c|c|c|c|}
\hline \multicolumn{3}{|c|}{ Macroscopic ABL (mm) } & Control & LPS & LPS + HU 308 \\
\hline \multirow{6}{*}{ Distance } & \multirow{3}{*}{ First upper molar } & Buccal & $1.25 \pm 0.16$ & $1.51 \pm 0.13$ & $1.28 \pm 0.16$ \\
\hline & & Palatal & $1.27 \pm 0.16$ & $1.51 \pm 0.22$ & $1.22 \pm 0.20$ \\
\hline & & Whole tooth & $2.52 \pm 0.09$ & $3.02 \pm 0.13^{*}$ & $2.50 \pm 0.11^{\#}$ \\
\hline & \multirow{3}{*}{ First lower molar } & Buccal & $1.08 \pm 0.15$ & $1.36 \pm 0.20^{*}$ & $1.25 \pm 0.19$ \\
\hline & & Lingual & $2.66 \pm 0.21$ & $3.70 \pm 0.42^{* * *}$ & $3.27 \pm 0.32 * \#$ \\
\hline & & Whole tooth & $3.74 \pm 0.10$ & $5.22 \pm 0.14^{* *}$ & $4.52 \pm 0.19^{* \#}$ \\
\hline Width & \multicolumn{2}{|l|}{ First lower molar } & $2.40 \pm 0.04$ & $2.34 \pm 0.03$ & $2.43 \pm 0.04$ \\
\hline
\end{tabular}

$\mathrm{ABL}$ of buccal and palata//lingual sides and whole tooth are shown for the first upper and lower molars. The width of the first lower molar is presented as a complementary evaluation.

$" \rho<0.05$, " $\rho<0.01$ and " $\rho<0.001$ vs. control; $" \rho<0.05$ vs. LPS. ABL: alveolar bone loss. LPS: lipopolysaccharide. HU 308 : synthetic agonist of the cannabinoid receptor 2 .

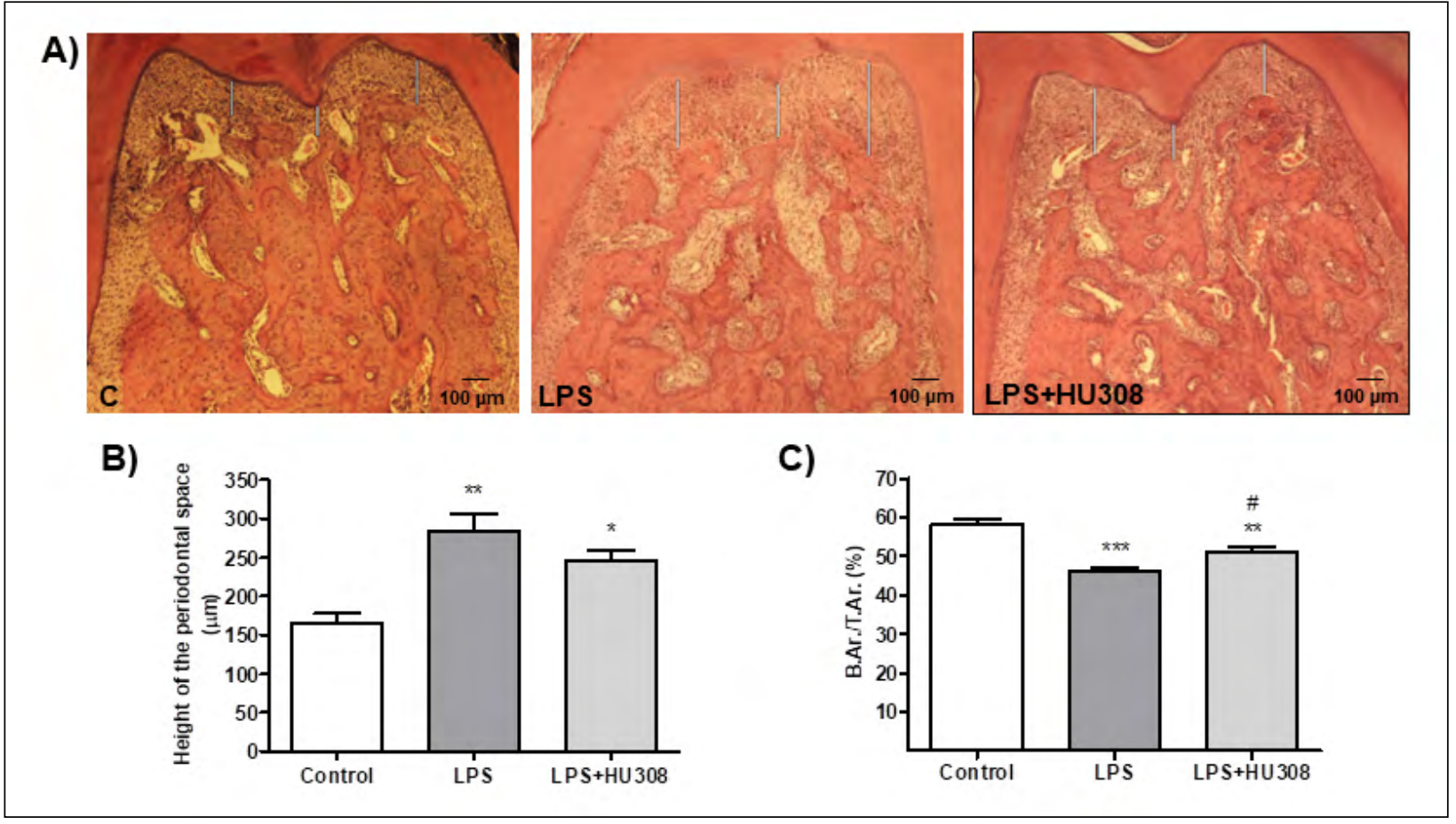

Fig. 1. A) Photomicrographs (H\&E stain; original magnification x40) showing histologic features of the mandibular first molar interradicular area of rats subjected to different experimental conditions (control, LPS and LPS $+H U$ 308). B) Periodontal space height evaluation. C) Interradicular bone measured as B.Ar/T.Ar (\%). Results are presented as mean $\pm S E M .{ }^{*} \rho<0.05$, ${ }^{* * *} \rho<0.01$ and ${ }^{* * *} \rho<0.001$ vs. control; ${ }^{*} \rho<0.05$ vs. LPS.

in comparison to controls, no significant difference was found between early-stage experimental periodontitis and HU 308-treated groups (Fig. 3). However, after the 3-week study period, a downward trend can be detected in the CB2r-agonist group with respect to early-stage experimental periodontitis.

\section{DISCUSSION}

Being one of the most prevalent disorders of the oral cavity, periodontal disease has been extensively studied in laboratory animals. To this end, endotoxin LPS-induced periodontitis has been a method which aimed to achieve a more physiological process of the spontaneous disease than traumatic methods ${ }^{24,25}$. The traumatic model consists of placing a ligature around molars and maintaining it, usually for two weeks, which produces a traumatic effect and facilitates dental plaque accumulation ${ }^{26}$. In the LPSinduced model, toxin reaches periodontal tissues and no traumatic effect is generated other than the needle 
A)

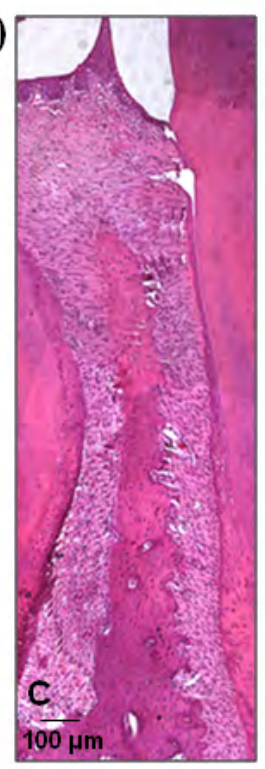

C)

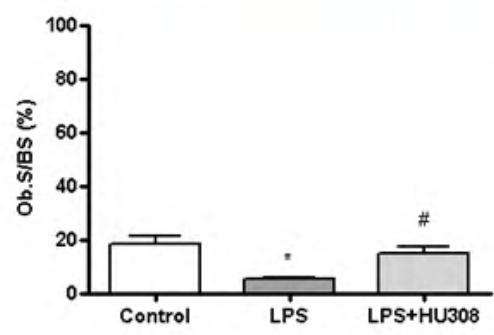

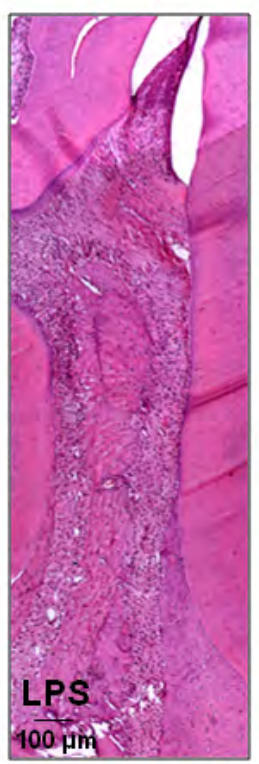

D)

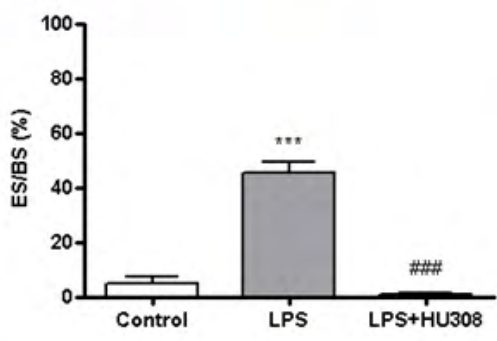

B)

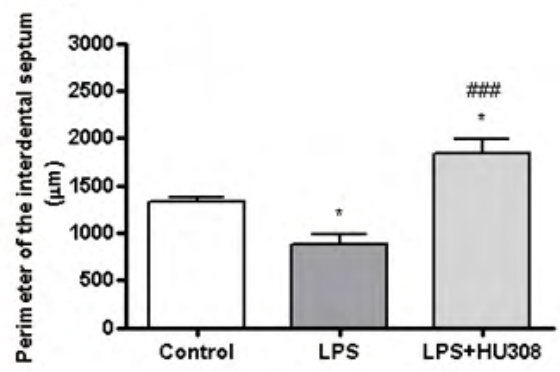

E)

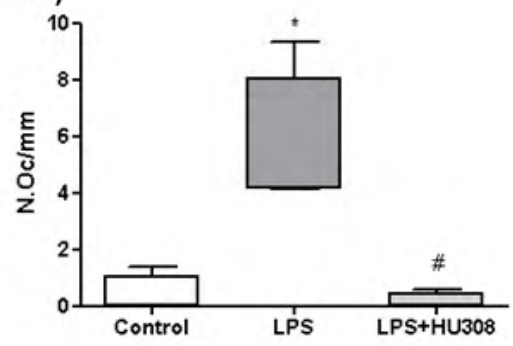

Fig. 2. A) Photomicrographs (H\&E stain; original magnification x100) showing histologic features of the interdental septum bone located between the first and the second lower molars of rats subjected to different experimental conditions (control, LPS and $L P S+H U$ 308). B) Whole perimeter of interdental septum bone expressed in $\mu m$. C) Bone formation surfaces expressed in \% as osteoblast surface/total bone surface (Ob.S/BS). D) Bone resorption surfaces expressed in \% as eroded surface/total bone surface $(E S / B S)$. E) Number of osteoclasts expressed as N.Oc/mm. Results are presented as mean $\pm S E M .{ }^{*} \rho<0.05$ and ${ }^{* * *} \rho<0.001$ vs. control; ${ }^{\prime} \rho<0.05$ and ${ }^{\# \#} \rho<0.001$ vs. LPS.

injection. However, scientific literature has not reached a consensus with regard to the characteristics of this model or to the terms used for the induction. Indeed, different authors have run trials lasting 1 to 10 weeks ${ }^{24,25,27-30}$. Moreover, in previous studies we have demonstrated that LPS injections in first molar gums for six weeks produce a set of chemical and anatomical changes in periodontal tissues ${ }^{14,16,31}$. At this time, the increase in alveolar bone loss and inflammatory mediators such as $\mathrm{TNF} \alpha, \mathrm{PGE}_{2}$ and nitric oxide (NO) in gingival tissues indicate that EP has been established. Therefore, in the current study, we firstly focused on evaluating conditions of periodontal disease at several periods of time in order to clarify the emergence and severity of the damage at earlier terms than six weeks.

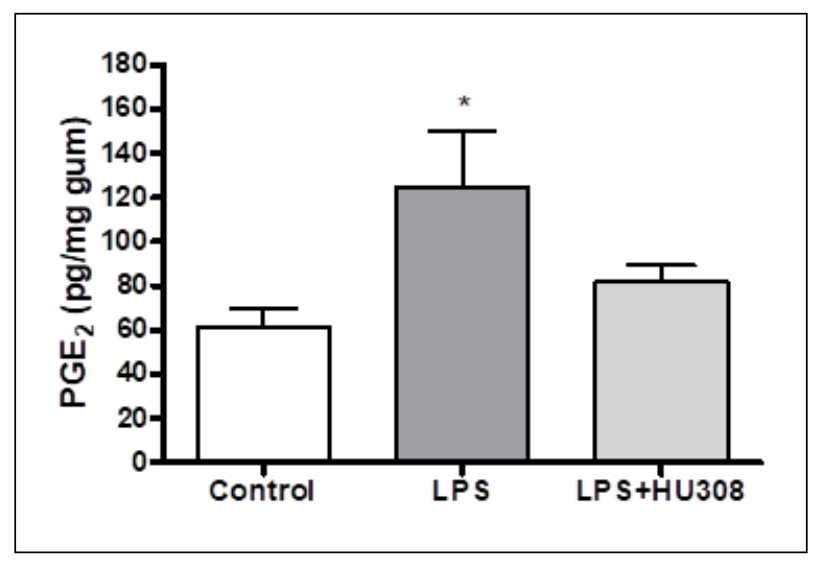

Fig. 3. Content of prostaglandin $E_{2}$ in gingival tissue: the effect of LPS and the application of HU 308. Results are presented as mean \pm SEM. ${ }^{*} \rho<0.05$ vs. control. 
We found that no alveolar bone loss was induced by LPS injections after one week of the treatment, whereas after three weeks, the alveolar bone loss by the distance method was significantly higher in the LPS-injected group than in the control group. Furthermore, the difference between groups was even more pronounced after six weeks, when the alveolar bone loss was also evident from the diminished width. Regarding $\mathrm{PGE}_{2}$ gingival content, results showed variability in control values among different times assessed in separate experiments, which could be associated with the high volatility and complicated biology of $\mathrm{PGE}_{2}$, in part due to the high number of $\mathrm{PGE}_{2}$ synthesizer cells and their variable response to the presence of antigens $^{32}$. Therefore, it is justified to analyse the results of each experiment separately. Despite these almost inevitable discrepancies, our results showed that gingival $\mathrm{PGE}_{2}$ content was significantly higher in LPS-induced periodontitis than in control rats at each assessed time.

Overall, these findings suggest that in early stages of LPS induction, even when alveolar bone damage is not clearly marked, gingival tissue expresses some sign of inflammation, a stage which could be related to gingivitis in human populations ${ }^{33}$. In addition, the first signs of alveolar bone loss at three weeks suggest that 3 weeks, or sometime between 1 and 3 weeks of LPS induction could be defined as the beginning of periodontitis in rats, though further studies are needed.

Since initial signs of alveolar bone loss were identified after three weeks, we subsequently assessed the effects of the HU 308 treatment at this time and considered it as an early stage of experimental periodontitis.

At 3-weeks, alveolar bone loss by the distance method increased on certain sides by LPS, was prevented in HU 308-treated rats. Some differences regarding control and LPS values between this study and the 3-week term assessed in the study time range might be caused by logical variability between experiments or due to random factors. In any case, distinct alveolar bone damage between control and LPS groups was also noticeable in this 3-week experiment, where even in group treated with HU 308, a mitigating effect emerged. In the histological analysis, the preventive effect of HU 308 on bone resorption was confirmed in the bone volume evaluation, even though a statistically non- significant tendency in the same direction could also be observed in the periodontal space evaluation. These results are consistent with those we found in the 6-week treatment, where these initial tendencies appeared to be strengthened. In fact, after six weeks, LPS-induced damage was clearer on both sides of the first upper and lower molars, while the HU 308 treatment efficiently attenuated $\mathrm{it}^{16}$. Furthermore, another study using in vitro human periodontal ligament cells demonstrated that LPS increases the concentration of IL- $1 b$, IL- 6 , TNF- $\alpha$, and RANKL, while HU 308 attenuates these parameters, normalizing bone metabolism ${ }^{34}$. On the other hand, histomorphometric measures on the interdental septum, such as perimeter of bone septum, bone formation areas, bone resorption areas and number of osteoclasts, lead to a scenario characterized by bone resorption in the LPS group and bone formation or resorption prevention in the HU 308-treated group. In this respect, in a recent study, Kamali et al. demonstrated the osteogenic effects of a scaffold based on cannabindiol, a natural cannabinoid, on bone defects in rats, employing histomorphometric measurements, among other techniques ${ }^{35}$.

$\mathrm{PGE}_{2}$ content evaluation in the gingival tissue showed a higher value in LPS-induced group with respect to controls, in agreement with the time range studies results. However, this increase was not significantly modified by the HU 308 treatment at three weeks, although a downward trend was evidenced. This result suggests that in a stage of emerging damage, HU 308 could start to show an incipient preventive effect, which is stronger and statistically significant at six weeks of induction ${ }^{20}$. Similarly, in our previous six-week study, other inflammatory mediators such as $\mathrm{TNF} \alpha$ and NO, which were increased in gums by LPS-induced periodontitis, also showed the reducing effect of the HU 308 treatment. Thus, attenuation of $\mathrm{PGE}_{2}$ in gingival tissue reveals the therapeutic potential of the CB2r stimulation, providing a potential way to reduce inflammatory and immune responses as well as to prevent bone resorption, probably through the regulation of osteoblast and osteoclast activity ${ }^{36}$.

In conclusion, a 3-week term of LPS-induced periodontitis is a valid model of the early stage of the disease, since emerging damage is expressed in bone tissue, although it is not as clear as in a 6-week term. Additionally, we demonstrated herein that 3-week harmful effects could be prevented by 
local stimulation of CB2r with HU 308. Current outcomes shortly after the beginning of LPSinduced periodontitis also support the importance of initiating interventions in early stages of the

\section{ACKNOWLEDGEMENTS}

Authors are very grateful to Cintia Cecilia Figueredo for her cooperation in reviewing the English language in the writing.

\section{FUNDING}

This work was supported by grants from the University of Buenos Aires, Argentina (UBACyT 2016/20020150100004BA), the National Agency for Scientific and Technological Promotion, Argentina (PICT-2016-0217) and the National Scientific and Technical Research Council of Argentina (CONICET, PIP2015-2017/045).

\section{REFERENCES}

1. Alshammari AS. Prevalence of different types of gingivitis and periodontitis in patients who attended periodontal clinic in ArAr specialist dental centre, a clinical survey study. Saudi J Oral Dent Res 2017; 2:38-42.

2. Stashenko P, Van Dyke T, Tully P, Kent R, Sonis S, Tanner AC. Inflammation and genetic risk indicators for early periodontitis in adults. J Periodontol 2011; 82: 588-596.

3. Surkin PN, Ossola CA, Mohn CE, Elverdin JC, FernándezSolari J. Chronic alcohol consumption alters periodontal health in rats. Alcohol Clin Exp Res 2014; 38: 2001-2007.

4. Abul K, Abbas AH, Lichtman JS. Inmunología celular y molecular (2nd ed.). Interamericana, McGraw Hill, 1995, 64-65.

5. Bapna M, Chauhan LS. The ambidextrous cyclooxygenase: an enduring target. Inflamm Allergy Drug Targets 2015; 13:387-392.

6. Offenbacher S, Heasman PA, Collins JG. Modulation of host PGE2 secretion as a determinant of periodontal disease expression. J Periodontol 1993; 64: 432-444.

7. Lomniczi A, Mohn C, Faletti A, Franchi A, McCann SM, Rettori V, Elverdin JC. Inhibition of salivary secretion by lipopolysaccharide: possible role of prostaglandins. Am J Physiol Endocrinol Metab 2001; 281: 405-411.

8. Genco RJ. Host responses in periodontal diseases: current concepts. J Periodontol 1992; 63: 338-355.

9. Konermann A, Jäger A, Held SAE, Brossart P, Schmöle A. In vivo and in vitro identification of endocannabinoid signaling in periodontal tissues and their potential role in local pathophysiology. Cell Mol Neurobiol 2017; 37: 1511-1520.

10. Concannon RM, Okine BN, Finn DP, Dowd E. Differential upregulation of the cannabinoid $\mathrm{CB}$ receptor in neurotoxic and inflammation-driven rat models of Parkinson's disease. Exp Neurol 2015; 269: 133-141.

11. Howlet A, Breivogel C, Childers S, Deadwyler S, Hampson R, Porrino L. Cannabinoid physiology and pharmacology: 30 years of progress. Neuropharmacol 2004; 47: 345-358.

12. Fukuda S, Kohsaka H, Takayasu A, Yokoyama W, et al. Cannabinoid receptor 2 as a potential therapeutic target in rheumatoid arthritis. BMC Musculoskelet Disord 2014; 15 : 275. pathology, before greater damage is produced, thereby preventing irreversible alterations of periodontal health in humans.

\section{CORRESPONDENCE}

Dr. César A. Ossola

Cátedra de Fisiologia, Facultad de Odontología,UBA

Marcelo T. de Alvear 2142, CABA.

Buenos Aires, Argentina

caossola@hotmail.com

13. Richardson JD, Kilo S, Hargreaves KM. Cannabinoids reduce hyperalgesia and inflammation via interaction with peripheral CB1 receptors. Pain 1998; 75: 111-119.

14. Ossola CA, Surkin PN, Pugnaloni A, Mohn C, Elverdin JC, Fernández-Solari J. Long-term treatment with methanandamide attenuates LPS-induced periodontitis in rats. Inflamm Res 2012; 61: 941-948.

15. Napimoga MH, Benatti BB, Lima FO, Alves PM, et al. Cannabidiol decreases bone resorption by inhibiting RANK/ RANKL expression and pro-inflammatory cytokines during experimental periodontitis in rats. Int Immunopharmacol 2009; 9: 216-222.

16. Ossola CA, Surkin PN, Mohn CE, Elverdin JC, FernándezSolari J. Anti-inflammatory and osteoprotective effects of cannabinoid-2 receptor agonist HU-308 in a rat model of lipopolysaccharide-induced periodontitis. J Periodontol 2016; 87: 725-734.

17. Gürkan A, Emingil G, Nizam N, Doğanavşargil B, Sezak M, Kütükçüler N, Atilla G. Therapeutic efficacy of vasoactive intestinal peptide in Escherichia coli lipopolysaccharideinduced experimental periodontitis in rats. J Periodontol 2009; 80: 1655-1664.

18. Prestifilippo JP, Fernández-Solari J, de la Cal C, Iribarne M, Suburo AM, Rettori,V, McCann SM, Elverdin JC. Inhibition of salivary secretion by activation of endocannabinoid receptors. Exp Biol Med 2006; 231: 1421-1429.

19. Crawford, J.M., Taubman, M.A., Smith, D.J. The natural history of periodontal bone loss in germfree and gnotobiotic rats infected with periodontopathic microorganisms. J Periodontal Res 1978; 13(4): 316-325.

20. Dempster DW, Compston JE, Drezner MK., Glorieux FH, et al. Standardized nomenclature, symbols, and units for bone histomorphometry: a 2012 update of the report of the ASBMR Histomorphometry Nomenclature Committee. J Bone Miner Res 2013; 28: 2-17.

21. Tang ZL, Zhang WJ, Wang DX, Chen JM, Ma H, Wu DR. An experimental study addressing the promotion of mandibular defect repair through the intermittent subcutaneous injection of parathyroid hormone. J Oral Maxillofac Surg 2014; 72: 419-430. 
22. Nenda MM,Lewicki M, Mandalunis PM. Histomorphometry of the tibia and mandible of healthy female Wistar rats at different stages of growth. Exp Anim 2016; 65: 109-116.

23. Mohn CE, Fernández-Solari J, De Laurentiis A, Bornstein SR, Ehrhart-Bornstein M, Rettori V. Adrenal gland responses to lipopolysaccharide after stress and ethanol administration in male rats. Stress 2011; 14: 216-226.

24. Llavaneras A, Golub LM, Rifkin BR, Heikkilä P, et al. CMT-8/clodronate combination therapy synergistically inhibits alveolar bone loss in LPS-induced periodontitis. Ann N Y Acad Sci 1999; 878: 671-674.

25. Ramamurthy NS, Xu JW, Bird J, BaxterA et al. Inhibition of alveolar bone loss by matrix metalloproteinase inhibitors in experimental periodontal disease. J Periodontal Res 2002; 37: 1-7.

26. Prestifilippo JP, Fernández-Solari J, Martinel Lamas DJ, Rios CE et al. Pharmacological targeting of histamine H4 receptor in periodontal disease. Oral Dis 2016; 22: 423-429.

27. Vardar S, Buduneli E, Baylas H, Berdeli AH, Buduneli $\mathrm{N}$, Atilla G. Individual and combined effects of selective cyclooxygenase- 2 inhibitor and omega-3 fatty acid on endotoxin-induced periodontitis in rats. J Periodontol 2005; 76: 99-106.

28. Rogers JE, Li F, Coatney DD, Rossa C et al. Actinobacillus actinomycetemcomitans lipopolysaccharide-mediated experimental bone loss model for aggressive periodontitis. J Periodontol 2007; 78: 550-558.

29. Nogueira AV, de Souza JA, de Molon RS, Pereira Eda $\mathrm{S}$, de Aquino SG, Gianobile WV, Cirelli JA. HMGB1 localization during experimental periodontitis. Mediators Inflamm 2014; 2014: 816320. doi: 10.1155/2014/816320
30. Wang PL, Oido-Mori M, Fujii T, Kowashi Y, et al. Effect of anti-CD14 antibody on experimental periodontitis induced by Porphyromonasgingivalis lipopolysaccharide. Jpn J Pharmacol 2002; 89: 176-183.

31. Ossola CA, Balcarcel NB, Astrauskas JI, Bozzini C, Elverdin, JC, Fernández-Solari, J. A new target to ameliorate the damage of periodontal disease: the role of transient receptor potential vanilloid type- 1 in contrast to that of specific cannabinoid receptors in rats. J Periodontol 2019; 90: 1325-1335.

32. Martínez-Colón GJ, Moore BB. Prostaglandin E2 as a Regulator of Immunity to Pathogens. Pharmacol Ther. 2018; 185:135-146.

33. Page RC, Schroeder HE. Pathogenesis of inflammatory periodontal disease. A summary of current work. Lab Invest 1976; 34: 235-249.

34. Qian H, Yi J, Zhou J, Zhao Y, Li Y, Jin Z, Ding Y. Activation of cannabinoid receptor $\mathrm{CB} 2$ regulates LPS-induced proinflammatory cytokine production and osteoclastogenic gene expression in human periodontal ligament cells. Open J Stomatol 2013; 3: 44-51.

35. Kamali A, Oryan A, Hosseini S, Ghanian MH, Alizadeh M, Baghaban Eslaminejad, M, Baharvand H. Cannabidiolloaded microspheres incorporated into osteoconductive scaffold enhance mesenchymal stem cell recruitment and regeneration of critical-sized bone defects. Mater Sci Eng C Mater Biol Appl 2019; 101: 64-75.

36. Fine PG, Rosenfeld MJ. The endocannabinoid system, cannabinoids, and pain. Rambam Maimonides Med J 2013; 4: e0022. doi: 10.5041/RMMJ.10129 